DOI: https://doi.org/10.15407/rpra23.04.244

PACS number: 98.35.-a

I. B. VAVILOVA, A. A. ELYIV, and M. YU. VASYLENKO

Main Astronomical Observatory, National Academy of Sciences of Ukraine,

27, Akademik Zabolotny St., Kyiv, 03143, Ukraine

Email: rivav@mao.kiev.ua; andrii.elyiv@gmail.com; maximka88@meta.ua

\title{
BEHIND THE ZONE OF AVOIDANCE OF THE MILKY WAY: WHAT CAN WE RESTORE BY DIRECT AND INDIRECT METHODS?
}

Purpose: to present a brief overview of methods for restoring the large-scale structure of the Universe behind the Zone of Avoidance (ZoA) of the Milky Way; to propose a new "algorithm of darning the ZoA" and new approach based on the Generative adversarial network (GAN) to recover galaxy distribution in the ZoA using optical surveys as an additional platform for programming the artificial neural networks.

Design/methodology/approach: Due to the extensive monitoring observations in radio (DOGS project, in HI line), infrared (IRAS and $2 M A S S$ surveys), and X-ray spectral ranges, the ZoA has been decreased significantly in size and now the obscured part is about $10 \%$ of the sky in the visible spectral range. The Cosmic Microwave Background (CMB) measurements showed a $180^{\circ}$ asymmetry known as the dipole: despite the fact that the resulting vector lies within $20^{\circ}$ of the observed CMB dipole, the calculations remain highly ambiguous, partly because the galaxies in the ZoA are not taken into account and the concept of "attractors" should be reconsidered. Hence, the analysis of the spatial distribution of galaxies and their groups in the regions surrounding and behind the ZoA of Milky Way remains a complex and unresolved problem, and estimation of the "invisible" content of the spatial galaxy distribution, which is obscured by this absorption zone, becomes a highly actual one. Restoring the ZoA is possible by indirect methods (signal processing applied to obscured and incomplete data; Voronoi tessellation, etc.). These recovery methods, however, work only for large-scale structures in the ZoA; they are practically not sensitive to individual galaxies and small galaxy systems. We suggest using the machine learning technique such as the GANfor modeling the "invisible" spatial galaxy distribution behind the ZoA.

Findings: We present "the algorithm of darning the ZoA" for dividing the real extragalactic surveys (e.g, the SDSS DR 14 galaxy sample) on the slices by redshifts, stellar magnitudes, coordinates and other parameters to form a training sample, and the general GAN scheme for the ZoA filling. We discuss principal tasks to generate galaxy distributions and their properties in the ZoA from latent space of features and describe how the discriminative network will compare the obtained artificial survey with the real one and evaluate how it is a realistic one.

Conclusions: The incompleteness of data depending on wavelengths indicates that there are steal not resolved problems such as the dynamics in the Local Group and the near Universe; the large-scale structure of the Universe in the sky region obscured by the Milky Way; the velocity flow fields towards the Great Attractor; the CMB dipole. Here, we propose a new "algorithm of darning the ZoA" and the general GAN scheme as an additional machine learning platform to recover a spatial distribution behind the ZoA of our Galaxy.

Key words: large-scale structure of the Universe, Milky Way, galaxies, galaxy clusters, zone of avoidance, machine learning, Generative adversarial network (GAN), "algorithm of darning the ZoA"

\section{Introduction}

The Zone of Avoidance of the Milky Way was firstly noted by R. Proctor in his paper as concerns with the "General Catalogue of Nebulae" by J. Herschel (1878): he called it as the Zone of Few Nebulae. In 1922, using the data from the "New General Catalogue" by Dreyer $(1888,1895)$, Charlier was the first who has referred this sky region as a scientific problem in recognizing the nebulae distribution in the area of the sky that is obscured by the Milky Way. In 1961, Shapley has proposed to call this region as the Zone of Avoidance (ZoA) delimited by "the isopleth of five galaxies per square degree from the Lick and

(C) I. B. Vavilova, A. A. Elyiv, M. Yu. Vasylenko, 2018

Harvard surveys". During the long time this zone was avoided by astronomers interested in the study of extragalactic objects due to 1) the small number of known objects; 2) decreasing the brightness of the extragalactic objects toward to the galactic equator; 3 ) increasing the concentration of stars on the line of sight which is resulted in increasing the overlapping of the extragalactic object with the star [1]. Because the Solar system is located not in the center of our Galaxy, the ZoA is also heterogeneous and longitudinal.

Since 1990s the notion of the ZoA galaxy distribution has changed significantly. If it was previously believed that this area closes an observer about $20 \%$ of the spatial distribution of galaxies in the optical 
range, then this value is now about $10 \%$. First of all, this has happened due to studies in the infrared and radio spectral ranges, since due to the decrease in the amount of light absorption with increasing wavelength, the Zone of Avoidance becomes more transparent in these spectral ranges. As for the incompleteness of ZoA galaxy catalogs as a function of the foreground extinction, we note that optical ZoA surveys are complete to an apparent diameter of $D=14^{\prime \prime}$ (where the diameters correspond to an isophote of $24.5^{\mathrm{m}} / \operatorname{arcsec}^{2}$ ) for extinction levels less than $A_{B}=3.0^{\mathrm{m}}$. The incompleteness of galaxy sample depending on the wavelength is an issue for studying dynamic properties of Local Group; the large-scale structure of the Universe (voids, filaments, walls, galaxy clusters, etc.); the velocity flow fields towards the Great Attractor; the dipole in the Cosmic Microwave Background (CMB), and other important problems.

In this paper, 1) we describe briefly in the Chapters 2 and 3 the direct (observational) and indirect methods (data mining plus confirmation through observations), which were provided to recognize celestial bodies in the ZoA; 2) we propose a new approach, the algorithm of darning the ZoA, based on the machine learning technique to reconstruct galaxy distribution in the ZoA, which takes into account the $3 \mathrm{D}$ distribution of galaxies and its photometry; the algorithm and a general scheme of the GAN machine learning methods are given in Chapter 4. The conclusions are made in Chapter 5.

\section{A Brief Review of the Direct and Indirect Methods for Restoring the Zone of Avoidance}

Due to the fact that galactic gas and dust close a significant part of the sky from visual observation, the detection of sources in this area becomes problematic. Due to the incomplete sampling in the area of absorption, on the basis of which the velocity field is constructed, we cannot say of its homogeneity, which gives an error in the definite direction of motion of our Galaxy by this method. The problem of the discrepancy between the vectors of movement of galaxies of the Local Group relative to the coordinate system associated with the $\mathrm{CMB}$ relict radiation suggests that there are a significant number of galaxies in the area of absorption of our Galaxy.
The methodology to solve this problem includes either direct or indirect techniques. Under direct methods is meant the observation of whole-sky surveys in different spectral ranges in the band near the galactic equator $\left(b \in\left[-20^{\circ},+20^{\circ}\right]\right)$. For example, the currently actively used method is the search for bright sources in the microwave energy range of regions of the heated gas and of areas of star formation HI. These areas are also monitored by radio telescopes with purpose to confirm the assumption of the presence of galaxies. In some cases, when sources can be visible in optical spectral range, this allows us to supplement the data on this source and the Tally-Fisher method to determine the distance to the galaxy.

\subsection{Observational Programs in IR-, Radio-, and X-ray Spectral Ranges}

The first qualitative breakthrough in the study of the ZoA belongs primarily to the Italian astronomer P. Maffei, who in 1968 discovered two galaxies in the ZoA using observations in the IR-range (see, paper by Maffei, 2003, for review of his own works [2]). The elliptical galaxy Maffei 1 together with its companion, spiral galaxy Maffei 2, was discovered on a hyper-sensitized I-N photographic plate exposed on 29 Sept 1967 with the Schmidt telescope at Asiago Observatory. These galaxies were named after as the Maffei 1 and the Maffei 2. For example, the last updated data about Maffei 1 are as follows: morphology E3, constellation Cassiopeia, RA $02^{\mathrm{h}} 36^{\mathrm{m}} 35.4^{\mathrm{s}}, \mathrm{DEC}+59^{\circ} 39^{\prime} 19^{\prime \prime}$, size 75,000 Ly $(23,000 \mathrm{pc})$, radial velocity $V_{r}=(66.4 \pm 5.0) \mathrm{km} / \mathrm{s}$, distance $(2.85 \pm 0.36) \mathrm{Mpc}$, stellar magnitude in visible range $m_{V}=11.14 \pm 0.06$. Maffei 1 is located only $0.55^{\circ}$ from the galactic plane in the middle of the $\mathrm{ZoA}$ and suffers from about $4.7^{\mathrm{m}}$ of extinction (a factor of about 1/70) in visible range. If there were no this absorption, it would be one of the largest and brightest elliptical galaxy in the sky (about 3/4 the size of the full moon).

The Maffei's discovery had a revolutionary effect for our modern picture of the Local Universe and promoted a lively discussion, first of all, about possible membership of these galaxies in the Local Group. We note several important papers on the determination of a distance to Maffei 1 to show how this problem was resolved. In 1970, Spinrad et al. [3] suggested that Maffei 1 is a nearby heavily obscured 
giant elliptical galaxy and the estimated distance to Maffei 1 is equal to $1 \mathrm{Mpc}$ (Local Group possible member?). In 1983 this estimate was revised up to 2.1 $1_{-0.8}^{+1.3}$ Mpc by Buta and McCall [4] (Maffei 1 is outside the Local Group!). In 2001, Davidge and van den Bergh [5], using adaptive optics to observe the brightest AGB stars in Maffei 1, concluded that distance is $4.4_{-0.5}^{+0.6} \mathrm{Mpc}$. So, these larger $(\geq 3 \mathrm{Mpc})$ distances reported in the past 20 years would imply that Maffei 1 has never been close enough to the Local Group to significantly influence its dynamics. The latest determination of the distance to Maffei 1 $((2.85 \pm 0.36) \mathrm{Mpc})$ is based on the re-calibrated luminosity/velocity dispersion relation for E-galaxies and the updated extinction. Maffei 1 is a key member of a nearby galaxy group, where among other large members are the giant spiral galaxies IC342 and Maffei $2[6,7]$. Maffei 1 has a small satellite spiral galaxy Dwingeloo 1, which was discovered in radio spectral range, as well as a number of dwarf satellites. The IC 342/Maffei Group is one of the closest galaxy groups to the Milky Way.

A significant progress in a magnificent reduction of the ZoA was connected with exploration of the IRAS and the 2MASS surveys. For example, in 2000, Jarret et al. [8] reported on the detection of newly discovered sources from 2MASS Extended Survey in the fields incorporating the Galactic plane at $l=40^{\circ}-70^{\circ}$ and predicted that the area-normalized detection rate is $\sim 1-2$ galaxies per $\mathrm{deg}^{2}$ brighter than $12.1^{\mathrm{m}}$ (10 mJy). See, also, earlier paper by $\mathrm{Lu}$ et al. [9] with results on identifying the HI spectra of galaxies observed by the IRAS.

Observations of the neutral hydrogen $(21 \mathrm{~cm})$ in frame of the DOGS project revealed new galaxies in the ZoA, the Dwingeloo 1 [10] and the Dwingeloo 2 [11] (see, for example, on the estimates of their kinematic and dynamic parameters, $[4,12,13])$. The DOGS project was conducted with $25 \mathrm{~m}$ Dwingeloo radio telescope and covered almost the whole observational region of the Northern Galactic Plane $l=30^{\circ}-200^{\circ}$ below a Galactic latitude $|b| \leq 5^{\circ}$. Because of the transparency of the Galaxy to the $21 \mathrm{~cm}$ radiation of neutral hydrogen, systematic HI-surveys are particularly powerful in mapping largescale structure (LSS) in this part of the sky. It should be noted that the absence of a signal does not always indicate the absence of a galaxy, but may be associated with a low HI content [14]. Nevertheless, that this method is slow and requires a lot of time, the conjunction of HI surveys and 2MASS will greatly increase the current census of galaxies hidden behind the Milky Way. Supplementary to these surveys, the Parkes Multibeam HI ZoA Survey as a systematic deep blind HI survey of the southern Milky Way was begun in 1997 with the Multibeam receiver at the $64 \mathrm{~m}$ Parkes telescope (surveys were centered on the southern Galactic Plane $52^{\circ} \leq l \leq 196^{\circ}$, $|b| \leq 5^{\circ}$ (see, for example, [15])).

The X-ray spectral range is an excellent window for studies of large-scale structure in the ZoA, because of the Milky Way is transparent to the hard Xray emission above a few $\mathrm{keV}$, also the rich clusters are strong X-ray emitters. Since the X-ray luminosity is roughly proportional to the cluster mass as $L_{X} \propto M^{3 / 2}$ or $M^{2}$, depending on the still uncertain scaling law between the X-ray luminosity and temperature (see our works [16-19] and references therein), massive clusters hidden by the Milky Way should be easily table through their X-ray emission $[20,21]$. This method is particularly attractive, because the clusters are primarily composed of earlytype galaxies, which are not recovered by IR galaxy surveys or by systematic HI surveys.

\subsection{A Brief Review of the Mathematical Simulation, Data Mining, and Machine Learning Methods}

Indirect methods consist in applying the mathematical simulation and data mining methods to fill the ZoA as well as to determine the gravitational potentials of the nearest galaxies in order to predict the positions of galaxies and galaxy systems in the area of Milky Way absorption. Now a great attention is also focused on the machine learning technique.

The inhomogeneous distributed mass of matter in the ZoA surrounding the Local Group may cause the unbalanced gravity toward the Local Group (LG) in one direction. The expected velocity of the Local Group can be calculated by the sum of gravitational forces from all known LG galaxies [22, 23]. Despite the fact that the resulting vector lies within $20^{\circ}$ of the observed cosmic background dipole, the calculations remain highly ambiguous, partly because galaxies in the ZoA are not taken into account $[24,25]$.

CMB measurements showed an $180^{\circ}$ asymmetry known as dipole. It manifests itself in the heating of $0.1 \%$ of $\mathrm{CMB}$ radiation in comparison with the average in one direction and in the same cooling in 
the opposite direction. These measurements have been confirmed yet by the COBE (1989-1990) studies indicating that the Milky Way and the Local Group are moving at a velocity $\sim V_{p}=627 \mathrm{~km} / \mathrm{s}$ to $l=276^{\circ}, b=30^{\circ}$, towards the Hydra constellation [26]. This motion arises as a result of the distribution of matter $M_{i}$ in the Local Group and depends on the cosmological parameter $\Omega_{0}$ [27]: $\vec{V}_{p} \propto \frac{\Omega_{0}^{0.6}}{b} \sum_{i} \frac{M_{i}}{r_{i}^{2}} \hat{r}_{i}$. The absence of objects in the absorption zone also plays a key role in determining the value of the dipole of the collective velocity of the galaxies. Filling the zone $|b| \leq 20^{\circ}$ by galaxies changes the direction of movement measured in the volume of $6000 \mathrm{~km} / \mathrm{s}$ by $31^{\circ}[28,29]$. Unknown galaxies that are closer to us in the ZoA can make a larger contribution to the definition of a vector of collective velocity than whole clusters over long distances: $\vec{V}_{p} \propto \sum_{i} 10^{-0.4 m} \hat{r}_{i}$.

What is the reason for this movement, which manifests itself in a slight deviation from the homogeneous expansion of the Universe? To overcame this discrepancy between the direction on the dipole and the expected velocity vector made it necessary to introduce the concept of "attractors" (the Great Attractor at a distance of about $60 \mathrm{Mpc}$ ). The Local Group is located at the same distance above the Perseus-Fornax cluster (both of which are components of a long chain of galaxies known as the Supergalactic Plane). However a lot of well known nearby large-scale structures are bisected by the Galactic Plane, such as the Local Supercluster, the PerseusPisces chain, and the Great Attractor. "What is their true extent and their mass? It is curious that the two major superclusters in the Local Universe, i.e. Perseus-Pisces and the Great Attractor overdensity, lie at similar distances on opposite sides of the Local Group, both partially obscured by the ZoA. Which one of the two is dominant in the tug-of-war on the Local Group? Do these features continue across the Galactic Plane and are there other massive structures hidden in the ZoA for which so far no indication exists? What is the size of the largest coherent structures?" - these questions remain unanswered. For instance, the Great Wall and the Perseus-Pisces chain are connected across the ZoA as it was suggested by Giovanelli \& Haynes [26] as the indicating structures of $(50-200) \mathrm{h}^{-1} \mathrm{Mpc}$. "The latter would be incompatible with the angular extent over which fluctuations - the seeds of current large-scale structures - have been measured in the CMB". To answer these questions, the superclusters need to be fully mapped across the ZoA. We should take into account that the ZoA is fully incomplete at low Galactic latitudes in the larger Galactic Bulge area $\left(l \approx 0^{\circ} \pm 90^{\circ}\right)$, including the Great Attractor region. Even if the obscured galaxies can be identified, the redshifts are determined very difficult if not impossible to obtain at the higher extinction levels.

Attempts to solve the problem of the incompatibility of the vector apex motion of the Local Group determined by the CMB and the velocity field did not give a positive result, since the method involves the uniform filling of the sky by the galaxies of the field, and chaotic filling them with non-real objects leads to the formation of non-existent fields [1]. This problem can be solved by the machine learning methods.

So, the intensive multi-wavelength surveys of the ZoA in the last decades were aimed at addressing such key problems as the cosmological questions about the dynamics of the Local Group, the possible existence of nearby hidden massive galaxies, the dipole determinations based on luminous galaxies, the continuity and size of nearby superclusters, the mapping of cosmic flow fields. Their solution is possible by indirect methods, which include the methods of signal processing applied to obscured and incomplete data; indirect estimates of averaged variables; the mask inversion using Wiener filtering in spherical harmonic analysis; reconstruction of the projected galaxy distribution in IR-, radio-, and X-ray spectral ranges; 2-D Wiener reconstruction to 3-D; methods of Voronoi mosaic, cluster and fractal analysis; machine learning technique.

In this way, for example, the coordinates and masses of new galaxy clusters in the Puppis and in the Vela constellations were calculated [29], as well as the length of the Supergalactic Plane in the ZoA. The velocities of the galaxies near the two edges of the ZoA were used to estimate the mass distribution in it. For example, the center of the Great Attractor was predicted to lie on a line joining the constellations Centaurus and the Pavo. The Norma Supercluster occupies region from $360^{\circ}$ to $290^{\circ}$ with a weakly visible extension towards Vela $\left(\sim 270^{\circ}\right)$. Puppis filament $\left(l \approx 240^{\circ}\right)$, the Hydra-Antlia filament $\left(l \approx 280^{\circ}\right)$, the overdense Great Attractor region $\left(l \approx 300^{\circ}-340^{\circ}\right)$ followed by an underdense region $\left(52^{\circ}<l<350^{\circ}\right)$, which is strongly influenced by the Local and Sagittarius Void [30]. 
Hence, till now the analysis of the spatial distribution of galaxies and their systems in the areas surrounding the Milky Way Avoidance Zone remains a complex and unresolved problem, as well as the estimation of the "invisible" content of the spatial galaxy distribution, which is obscured by this absorption zone. The last successful results based on the 2MASS Tully-Fisher Survey and the HI observational surveys are presented in works by Said et al. [32-34], where the optimized Tully-Fisher relation allowing accurate measures of galaxy distances and peculiar velocities for dust-obscured galaxies is also applied.

\section{Scientific Problems as Concerns with Incompleteness of the Data on the Spatial Distribution in the Sky Area Obscured by the Milky Way. Gaps in Spectroscopic Observations}

A state-of-art approach as concern with incompleteness of the data is to use observations of galaxies and their systems that surround the ZoA to reconstruct missing information in it $[25,35,36]$. The study should be conducted within the limited modeling of the Local Universe and unlike ordinary cosmological simulations, these simulations has restrictions on the initial conditions limited by observational data. Thus, these observations may concerns with either own radial velocities of galaxies or redshift catalogues.

Classical 3D reconstruction of the extragalactic objects behind the Milky Way to preserve the coherence of the large scale structure was triggered by the search of the Great Attractor in the 1990s [31]. Problem of ZoA reconstruction is related to dealing with gaps in the spectroscopic observations to restore homogeneous sky coverage. A good example is the wide field imager and a multi-object spectrograph (VIMOS) at the European Southern Observatory's Very Large Telescope. It consists of the 4 CCDs with 2 arcmin space between them; the total area coverage is $290 \operatorname{arcmin}^{2}$. Almost $25 \%$ of the field is the unobserved region due to the constructed gaps between the CCDs. It means that for $\approx 25 \%$ galaxies in sample is not possible to get spectroscopic redshifts just less accurate photometric ones are presented. Such regular pattern, which corresponds to footprint of the spectrograph, creates issues for VIMOS Public Extragalactic Redshift Survey (VIPERS). Especially it creates the systematic effects of the violation of the local Poisson hypothesis in cell coun- ting statistics and makes galaxy counts in cells measurements non valid [37].

Existing of unobserved zones in scales comparable to size of investigated zone can have a serious impact on the study of galaxy properties and local environment. In this case the local and deterministic recovery of the missing data is needed [38]. For small scale reconstruction are common such techniques as the direct cloning [39], wavelet analysis $[40,41]$, cluster analysis $[42,43,44]$, randomized cloning of objects into unobserved areas or application of the Wiener Filtering [45, 46], Voronoi tessellation [47-50]. Cucciati et al. proposed two algorithms [51] that use photometric redshift of target objects and assign redshifts based on the spectroscopic redshifts of the nearest galaxies. A Wiener filter applied in this work was very efficient also to reconstruct the continuous density field instead of individual galaxy positions. This is a Bayesian method with basic assumptions that both the distribution of the overdensity field and the likelihood of observing galaxies are distributed by Gaussian. A true density distribution is reconstructed by maximizing the posterior distribution given by Bayes formula. These methods can clearly separate underdense from overdense regions on scales of $5 \mathrm{~h}^{-1} \mathrm{Mpc}$ at moderate redshifts $0.5<z<1.1$, which is important for studies of cosmic variance and rare population galaxy systems.

\section{Generative Adversarial Neural Networks for Recovering Damaged Astronomical Images and Surveys}

Optical observations of extended objects are limited by random and systematic noise from detector, telescope system and sky background. An image from telescope can be interpreted as a convolution of the real image with point spread function (PSF) and some noise. The Shannon-Nyquist sampling theorem demonstrates limits of deconvolution technique for improving the observed images [52]. From other side, there is no unique solution at deconvolution $[53,54)$. Schawinski et al. estimated a possibility to recover artificially degraded images with a high noise better than a simple deconvolution can do [55]. They proposed to use stateof-the-art methods of Machine Learning, namely Deep Learning - Generative adversarial network (GAN). In case of galaxy images when we know how they should look like, this information can be helpful for decisions while choosing among many solutions. 
Generative adversarial neural networks as the type of the unsupervised machine learning algorithms were firstly invented by Goodfellow et al. in 2014 [56]. Core of these classes of algorithms are two neural networks contesting with each other in a zero-sum game. First neural network called "generative" (typically a deconvolutional), generates candidate images and second neural network (a convolutional discriminative) evaluates them. The generative network trains to transfer from a space of features to a particular data distribution. In the same time the discriminative network discriminates between the produced candidates and real examples. Schawinski et al. [55] applied the GAN to 4550 galaxies from the Sloan Digital Sky Survey DR12 (SDSS DR12). The authors have proved that this method can reliably recover features in images of galaxies and can go well beyond the limitation of deconvolutions. As the training sample they used image pairs: one original image of galaxy and the same artificially degraded (convolved with PSF). In general, the GAN is going to learn how to recover the degraded image by minimizing the difference between the recovered and true images. A main feature of this approach is the measurement of the difference between these two images called the loss function. With this purpose, the authors used a second neural network, whose aim is to distinguish the synthetic recovered image from true image. These two neural networks are trained simultaneously. Therefore by training on higher quality images, the GAN method can learn how to recover information from the less quality data by building priors. Such approach has a potential for recovering partially damaged images with gaps, dead CCD chips, ZoA etc.

We propose to apply such approach to the sample of galaxies from the SDSS DR14 (a general galaxy distribution at the redshifts $z<1$ is shown in Fig. 1(a), a galaxy distribution in the ZoA is shown in Fig. 1(b). A general scheme of the GAN approach for the filling of the $\mathrm{ZoA}$ in extragalactic surveys is shown in Fig. 2. Principal problem with a whole-sky galaxy distribution is that we have just unique sample of galaxies, i.e. just one set for training. We cannot use a set of many images for training likely in the approach described above. A solution could be to prepare the mock catalogues from numerical simulations, which reproduce a target sample. In this case we may generate as much as possible pairs - real survey and survey with ZoA. Additionally position of the ZoA could be randomized over survey field.
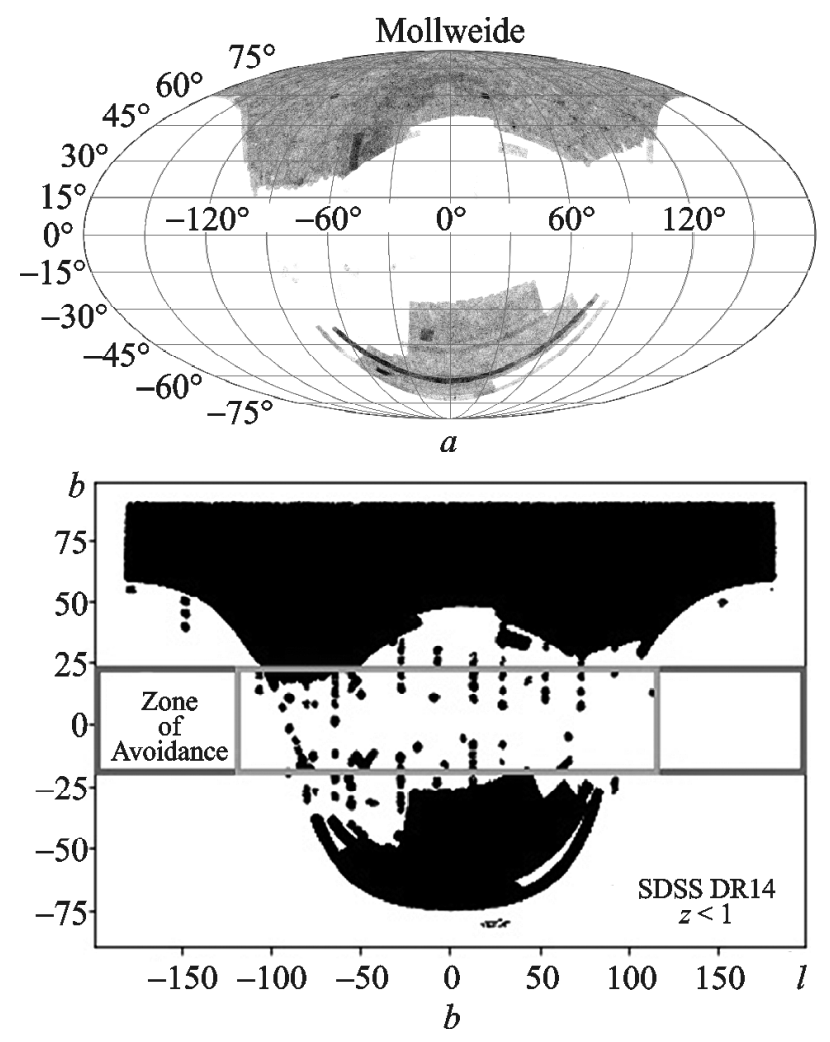

Fig. 1. Distribution of galaxies from the SDSS DR14 at the redshifts $z<1$ in Galactic coordinates: $(a)$ whole-sky distribution (Mollweide projection); $(b)$ in the ZoA

A goal of generative artificial neural network (ANN) will be in the trying to generate galaxy distributions and their properties in the ZoA from latent space of features. In the same time, a discriminative network will compare the obtained survey with the real one and evaluate how realistic it is. The generative network produces better surveys with iteration, while the discriminative one becomes more experienced at labeling the synthetic ones. In such a way the system learns the sophisticated loss functions automatically without its predefinition.

The "algorithm of darning the ZoA" for dividing the real extragalactic surveys (for example, SDSS or 2MASS, or future $\mathrm{LSST}^{1}$ survey) on the slices by redshifts, stellar magnitudes, coordinates and other parameters to form a training sample is given in Fig. 3. To apply the algorithm, we should prepare a sample of galaxies surrounding the $\mathrm{ZoA}$, which is complete by stellar magnitudes. To get a 3D spatial distribution of galaxies in this sample, we must obtain their pho-

${ }^{1}$ https://www.1sst.org/sites/default/files/docs/137.25_Borne_Data_ Mining_Research_8x10.pdf 


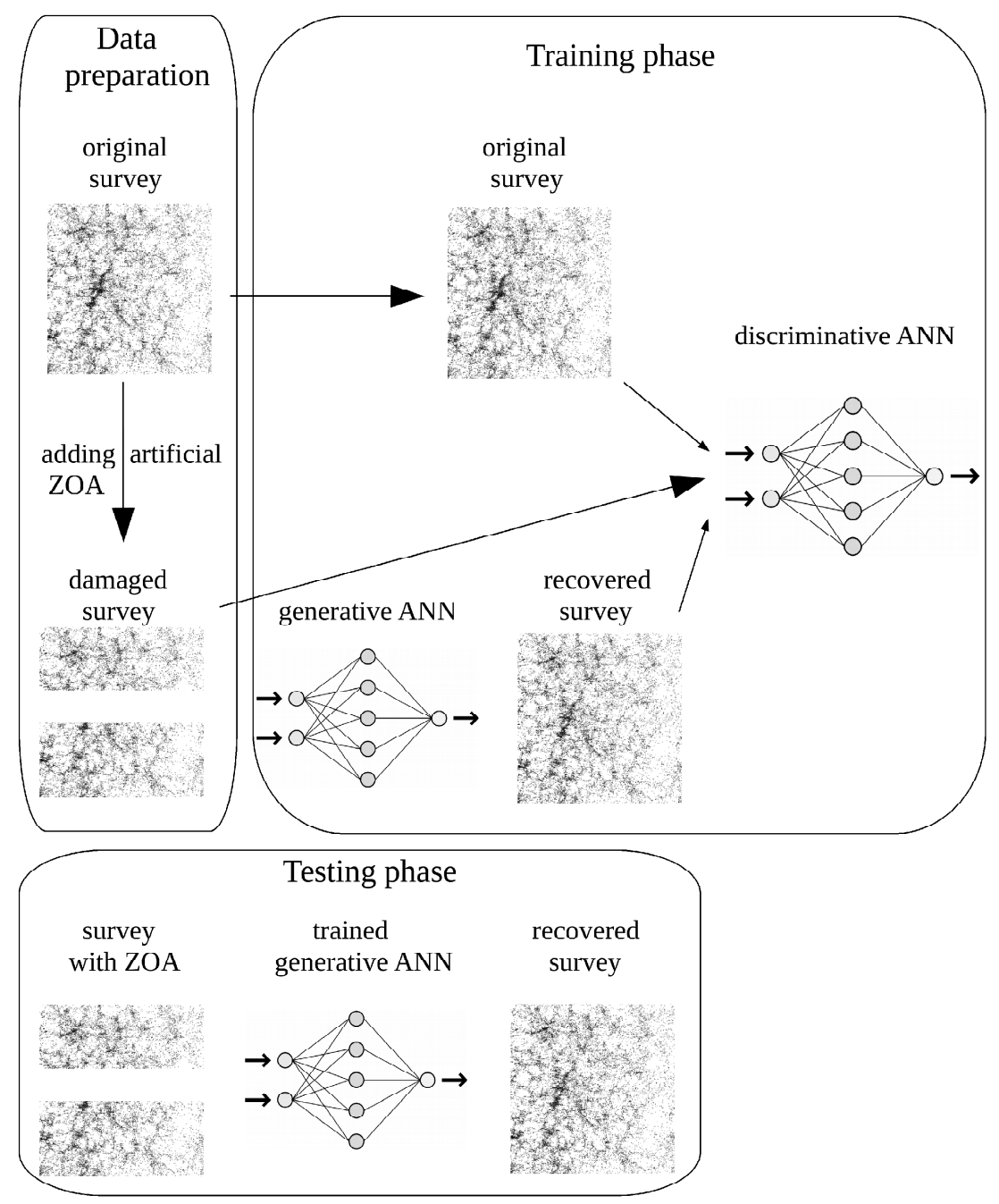

Fig. 2. Scheme of the data preparation, the training and testing phases for the ZoA recovering by the GAN method. The input is a set of mock surveys from which the artificial ZoA were generated to train the GAN. A generative ANN is used to recover surveys in the ZoA at the testing phase

tometric redshifts and to divide this sample on the slices by coordinates, taking into account the cosmological parameters. Each of these slices will contain a real distribution and the damaged image (part of the ZoA region), which will require a darning. The preliminary step how the algorithm works and restores a galaxy distribution should be conducted and tested with subsamples of real galaxies selected from the non-damaged regions. The information about morphological classification of galaxies will be useful at this step and can be obtained by another machine learning technique (see, for example, our works [57] on applying the Random Forest methods to obtain a binary morphological classification (early and late types) or ternary classification, which requires knowledge on the color indices and photometry of galaxies). Another data mining methods such as the Data visualization, SelfOrganizing Map, Classification, Bayesian Analysis as well as $3 \mathrm{D}$ print models will be also engaged.

\section{Conclusions}

We presented a brief overview of methods for restoring the large-scale structure of the Universe behind the Zone of Avoidance (ZoA) of the Milky Way. Among them are the direct methods, which are concerns with observational programs in IR-, radio, and X-ray spectral ranges (IRAS, 2MASS, HI surveys etc.). Due to their complanatory with optical databases the new galaxies and their systems were discovered that allowed decreasing a size of the ZoA (now it closes an observer about $10 \%$ of the spatial 


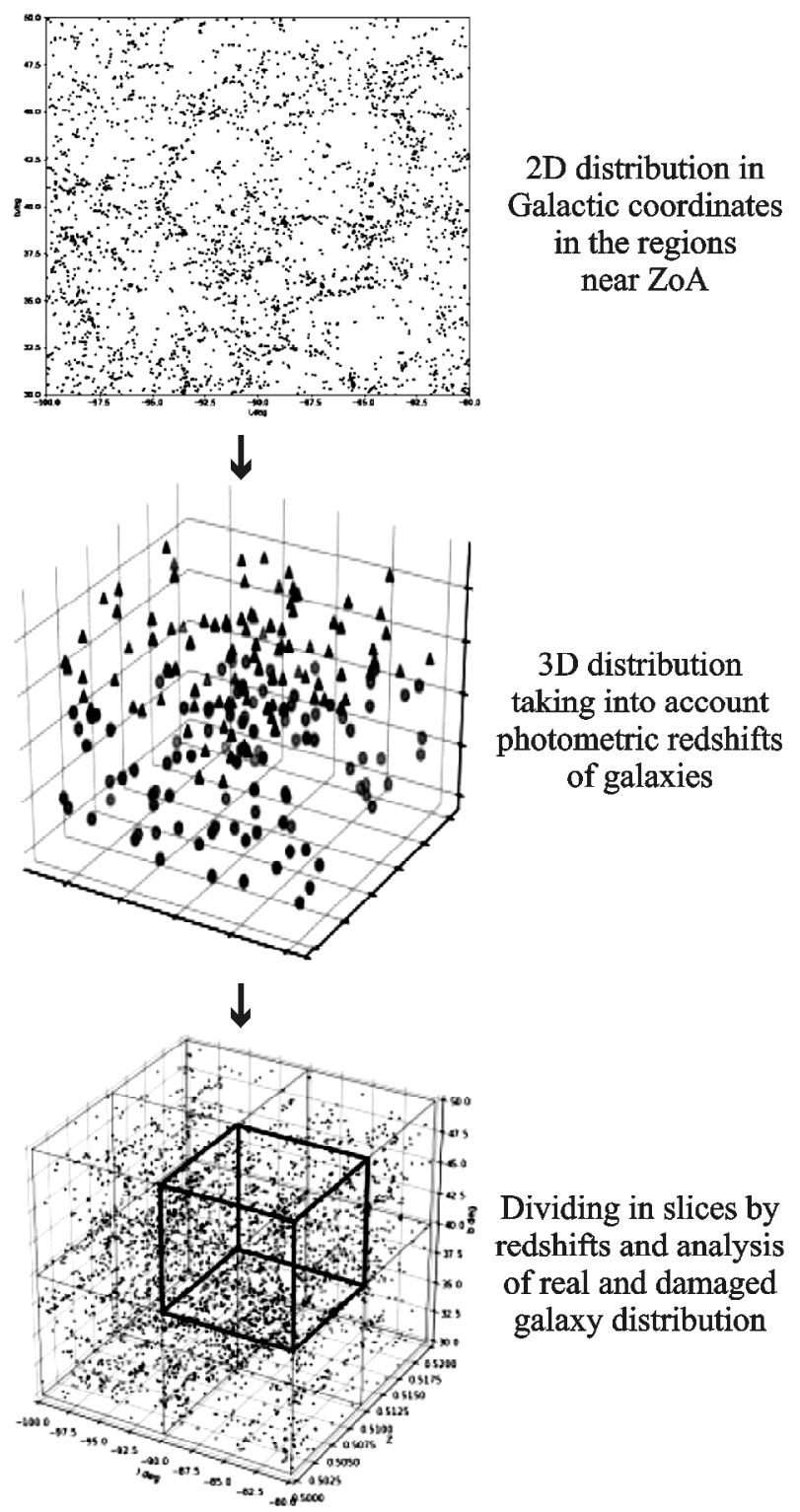

- To prepare a sample of galaxies that is complete by stellar magnitudes

- To analyze the slices divided by redshifts for selecting regions with real galaxy distribution outside of the ZoA at higher latitudes for creation a training sample

- To analyze the slices divided by redshifts for selecting regions with real and damaged distributions of galaxies in regions, which surround the ZoA

- To restore a spatial galaxy distribution (3D darning) in the $\mathrm{ZoA}$

Fig. 3. The algorithm of 3D "darning" of a spatial distribution in the ZoA of the Milky Way (galaxy simple from the SDSS DR14 at $z<1$ is shown as the example)

distribution of galaxies in the optical range. We also described briefly the indirect methods for restoring the ZoA, which were applied successfully with this purpose (methods of average variables, mathematical simulation, data mining, machine learning). Nevertheless, the filling of the ZoA remains a complex and unresolved problem, as well as the recognition of the invisible content of the spatial galaxy distribution, which is obscured by this absorption zone, is a highly actual. We described 1) the algorithms of "darning" the ZoA, which takes into account the photometric redshifts of galaxies surrounding the ZoA, and 2) new approach based on the Generative adversarial network (GAN) to recover galaxy distribution in the ZoA using optical surveys as an additional platform for programing the artificial neural networks.

The work was partially supported in frame of the Target Complex Program of Scientific Space Research of the NAS of Ukraine (2018-2022).

\section{REFERENCES}

1. Kraan-Korteweg R. C. and Lahav O. The Universe behind the Milky Way. Astron. Astrophys. Rev. 2000. Vol. 10, No. 3. P. 211-261. DOI: 10.1007/s001590000011

2. Maffei P. My Researches at the Infrared Doors. Mem. S. A. It. 2003. Vol. 74, No. 1. P. 19-28.

3. Spinrad H., Sargent W. L. W., Oke J. B., Neugebauer G., Landau R., King I. R., Gunn J. E., Garmire G., and Dieter N. H. Maffei 1: a New Massive Member of the Local Group? Astrophys. J. 1971. Vol. 163. id. L25. DOI: 10.1086/ 180660

4. Buta R. J. and McCall M. L. The IC 342/Maffei Group Revealed. Astrophys. J. Suppl. Ser. 1999. Vol. 124. P. 33-93. DOI: $10.1086 / 313255$

5. Davidge T. J. and van den Bergh S. The Detection of Bright Asymptotic Giant Branch Stars in the Nearby Elliptical Galaxy Maffei 1. Astrophys. J. 2001. Vol. 553, Is. 2. id. L133. DOI: $10.1086 / 320692$

6. Huchtmeier W. K., Lercher G., Seeberger R., Saurer W., and Weinberger R. Two new possible members of the IC342-Maffeil/2 group of galaxies. Astron. Astrophys. 1995. Vol. 293. P. L33-L36.

7. Karachentsev I. D., Sharina M. E., Dolphin A. E., and Grebel E. K. Distances to nearby galaxies around IC 342. Astron. Astrophys. 2003. Vol. 408. P. 111-118. DOI: 10.1051/0004-6361:20030912

8. Jarrett T. H., Chester T., Cutri R., Schneider S., Rosenberg J., Huchra J. P., and Mader J. 2MASS Extended Sources in the Zone of Avoidance. Astron. J. 2000. Vol. 120, Is. 1. P. 298-313. DOI: 10.1086/301426

9. Lu N. Y., Dow M. W., Houck J. R., Salpeter E. E., and Lewis B. M. Identifying galaxies in the zone of avoidance. Astrophys. J. 1990. Vol. 357. P. 388-407. DOI: 10.1086/ 168929

10. Kraan-Korteweg R. C., Loan A. J., Burton W. B., Lahav O., Ferguson H. C., Henning P. A., and Bell L. D. Discovery of a nearby spiral galaxy behind the Milky Way. Nature. 1994. Vol. 372, Is. 6501. P. 77-79. 
11. Burton W. B., Verheijen M. A., Kraan-Korteweg R. C., and Henning P. A. Neutral hydrogen in the nearby galaxies Dwingeloo 1 and Dwingeloo 2. Astron. Astrophys. 1996. Vol. 309. P. 687-701.

12. Huchtmeier W. K., Lercher G., Seeberger R., Saurer W., and Weinberger R. Two new possible members of the IC342-Maffei1/2 group of galaxies. Astron. Astrophys. 1995. Vol. 293L. P. L33-L36.

13. Karachentsev I. D. The Local Group and Other Neighboring Galaxy Groups. Astron. J. 2005. Vol. 129, No. 1. P. $178-188$. DOI: $10.1086 / 426368$

14. Lahav O., Brosch N., Goldberg E., Hau G. K. T., KraanKorteweg R. C., and Loan A. J. Galaxy candidates in the Zone of Avoidance. Mon. Not. R. Astron. Soc. 1998. Vol. 299, Is. 1. P. 24-30. DOI: 10.1046/j.1365-8711.1998. 01686.x

15. Saurer W., Seeberger R., and Weinberger R. Penetrating the "zone of avoidance". IV. An optical survey for hidden galaxies in the region $-130^{\circ} \leq l \leq 130^{\circ},-5^{\circ} \leq l \leq+5^{\circ}$. Astron. Astrophys. Suppl. Ser. 1997. Vol. 126, No. 1. P. 247-250. DOI: 10.1051/aas:1997385

16. Babyk Iu. V. and Vavilova I. B. The Distribution of Baryon Matter in the Nearby X-ray Galaxy Clusters. Odessa Astronomical Publications. 2012. Vol. 25, Is. 2. P. 119-124.

17. Babyk Iu. V. and Vavilova I. B. Comparison of Optical and X-ray Mass Estimates of the Chandra Galaxy Clusters at $z<0.1$. Odessa Astronomical Publications. 2013. Vol. 26. P. 175-178.

18. Babyk Iu. and Vavilova I. The Chandra X-ray galaxy clusters at $z<0.4$ : constraints on the evolution of $\mathrm{L}_{\mathrm{X}}-\mathrm{T}-\mathrm{M}_{\mathrm{g}}$ relations. Astrophys. Space Sci. 2014. Vol. 349, Is. 1. P. 415-421. DOI: $10.1007 / \mathrm{s} 10509-013-1630-\mathrm{Z}$

19. Babyk Iu. V., Del Popolo A., and Vavilova, I. B. Chandra X-ray galaxy clusters at $z<0.4$ : Constraints on the inner slope of the density profiles. Astron. Rep. 2014. Vol. 58, No. 9. P. 587-610. DOI: 10.1134/S1063772914090017

20. Kocevski D. D., Ebeling H., and Mullis C. R. Clusters in the Zone of Avoidance. In: Carnegie Observatories Astrophysics Series. Vol. 3: Clusters of Galaxies: Probes of Cosmological Structure and Galaxy Evolution. J. S. Mulchaey, A. Dressler, and A. Oemler, eds. 2003. URL: http://cds.cern.ch/record/614259/files/0304453.pdf

21. Ebeling H., Jones L. R., Fairley B. W., Perlman E., Scharf C., and Horner D. Discovery of a Very X-Ray Luminous Galaxy Cluster at $z=0.89$ in the Wide Angle ROSAT Pointed Survey. Astrophys. J. 2001. Vol. 548, Is. 1. P. L23-L27. DOI: $10.1086 / 318915$

22. Karachentsev I. D., Makarov D. I., and Kaisina E. I. Updated Nearby Galaxy Catalog. Astron. J. 2013. Vol. 145, Is. 4. id. 101. DOI: 10.1088/0004-6256/145/4/101

23. Kashibadze O. G., Karachentsev I. D., and Karachentseva V. E. Surveying the Local Supercluster Plane. Astrophys. Bull. 2014. Vol. 73, No. 2. P. 124-141. DOI: 10.1134/ S1990341318020025

24. Vavilova I. B. Wavelet analysis as approach to recognize abundance zone in galaxy distribution. Kinematika i Fizika Nebesnykh Tel. 2000. Vol. 16(3). P. 155.

25. Erdoğdu P. and Lahav O. Is the misalignment of the Local Group velocity and the dipole generated by the $2 \mathrm{MASS}$ Redshift Survey typical in $\Lambda$ cold dark matter and the halo model of galaxies? Phys. Rev. D. 2009. Vol. 80, Is. 4. id. 043005. DOI: 10.1103/PhysRevD.80.043005

26. Kogut A., Lineweaver C., Smoot G. F., Bennett C. L., Banday A., Boggess N. W., Cheng E. S., de Amici G., Fixsen D. J., Hinshaw G., Jackson P. D., Janssen M., Keegstra P., Loewenstein K., Lubin P., Mather J. C., Tenorio L., Weiss R., Wilkinson D. T., and Wright E. L. Dipole anisotropy in the COBE DMR first year sky maps. Astrophys. J. 1993. Vol. 419. DOI: 10.1086/173453

27. Giovanelli R. and Haynes M. P. A $21 \mathrm{~cm}$ survey of the Pisces-Perseus supercluster. I - The declination zone +27.5 to +33.5 degrees. Astron. J. 1985. Vol. 90, Is. 12 . P. 2445-2473. DOI: $10.1086 / 113949$

28. Kolatt T. and Dekel A. Large-scale power spectrum from peculiar velocities. Astrophys. J. 1997. Vol. 479, No. 2. P. 592-605.

29. Vasylenko M. Yu. and Kudrya Yu. N. Dipole bulk velocity based on new data sample of galaxies from the catalogue 2MFGC. Adv. Astron. Space. Phys. 2017. Vol. 7, Is. 1-2. P. 6-11. DOI: 10.17721/2227-1481.7.6-11

30. Kraan-Korteweg R. C., Cluver M. E., Bilicki M., Jarrett T. H., Colless M., Elagali A., Böhringer H., and Chon G. Discovery of a supercluster in the ZOA in Vela. Mon. Not. R. Astron. Soc. 2016. Vol. 466, Is. 1. P. L29-L33. DOI: $10.1093 / \mathrm{mnras} / \mathrm{slw} 229$

31. Kraan-Korteweg R. C. Cosmological Structures behind the Milky Way. In: S. Röser, ed. Reviews in Modern Astronomy 18: From Cosmological Structures to the Milky Way. New York: Wiley, 2005. P. 48-75.

32. Said K., Kraan-Korteweg R. C., and Jarrett T. H. Galaxy peculiar velocities in the Zone of Avoidance. In: Proc. SAIP2013, the 58th Annual Conference of the South African Institute of Physics. R. Botha and T. Jil, eds. 2014. arXiv: 1410.2992

33. Said K., Kraan-Korteweg R. C., Staveley-Smith L., Williams W. L., Jarrett T. H., and Springob C. M. NIR TullyFisher in the Zone of Avoidance - II. $21 \mathrm{~cm}$ HI-line spectra of southern ZOA galaxies. Mon. Not. R. Astron. Soc. 2016. Vol. 457, Is. 3. P. 2366-2376. DOI: 10.1093/mnras/ stw 105

34. Said K., Kraan-Korteweg R. C, Jarrett T. H., StaveleySmith L., and Williams, W. L. NIR Tully-Fisher in the Zone of Avoidance - III. Deep NIR catalogue of the HIZOA galaxies. Mon. Not. R. Astron. Soc. 2016. Vol. 462, Is. 3. P. 3386-3400. DOI: $10.1093 / \mathrm{mnras} / \mathrm{stw} 1887$

35. Courtois H. M., Hoffman Y., Tully R. B, and Gottlöber S. Three-dimensional Velocity and Density Reconstructions of the Local Universe with Cosmicflows-1. Astrophys. $J$. 2012. Vol. 744, Is. 1. id. 43. DOI: $10.1088 / 0004-637 \mathrm{X} /$ $744 / 1 / 43$

36. Sorce J. G., Colless M., Kraan-Korteweg R. C., and Gottlöeber S. Predicting Structures in the Zone of Avoidance. Mon. Not. R. Astron. Soc. 2017. Vol. 471, Is. 3. P. 3087-3097. DOI: $10.1093 / \mathrm{mnras} / \mathrm{stx} 1800$

37. Bel J., Marinoni C., Granett B. R, Guzzo L., Peacock J. A., Branchini E., Cucciati O., de la Torre S., Iovino A., Percival W. J., Steigerwald H., Abbas U., Adami C., Arnouts S., Bolzonella M., Bottini D., Cappi A., Coupon J., Davidzon I., De Lucia G., Fritz A., Franzetti P., Fumana M., Garilli B., Ilbert O., Krywult J., Le Brun V., Le Fèvre O., Maccagni D., Małek K., Marulli F., McCracken H. J., 
Paioro L., Polletta M., Pollo A., Schlagenhaufer H., Scodeggio M., Tasca L. A. M., Tojeiro R., Vergani D., Zanichelli A., Burden A., Di Porto C., Marchetti A., Mellier Y., Moscardini L., Nichol R. C., Phleps S., Wolk M., and Zamorani G. The VIMOS Public Extragalactic Redshift Survey (VIPERS) $\Omega_{\mathrm{m}_{0}}$ from the galaxy clustering ratio measured at $z \sim 1$. Astron. Astrophys. 2014. Vol. 563. id. A37. DOI: 10.1051/0004-6361/201321942

38. Cucciati O., Iovino A., Marinoni C., Ilbert O., Bardelli S., Franzetti P., Le Fèvre O., Pollo A., Zamorani G., Cappi A., Guzzo L., McCracken H. J., Meneux B., Scaramella R., Scodeggio M., Tresse L., Zucca E., Bottini D., Garilli B., Le Brun V., Maccagni D., Pica J. P., Vettolani G., Zanichelli A., Adami C., Arnaboldi M., Arnouts S., Bolzonella M., Charlot S., Ciliegi P., Contini T., Foucaud S., Gavignaud I., Marano B., Mazure A., Merighi R., Paltani S., Pellò R., Pozzetti L., Radovich M., Bondi M., Bongiorno A., Busarello G., de la Torre S., Gregorini L., Lamareille F., Mathez G., Mellier Y., Merluzzi P., Ripepi V., Rizzo D., Temporin S., and Vergani D. The VIMOS VLT Deep Survey: the build-up of the colour-density relation. Astron. Astrophys. 2006. Vol. 458, Is. 1. P. 39-52. DOI: 10.1051/0004-6361:20065161

39. Elyiv A. A. UHECRs deflections in the IRAS PSCz catalogue based models of extragalactic magnetic field. Eprint arXiv.org. 2006. arXiv:astro-ph/0611696

40. Vavilova I. B. Cluster and wavelet analysis for detachment of the structure of galaxy cluster: comparison. In: Data Analysis in Astronomy, Proc. of the Fifth Workshop. V. Di Gesu, M. J. B. Duff, A. Heck, M. C. Maccarone, L. Scarsi and H. U. Zimmerman, eds. World Scientific Press, 1997. P. 297-302.

41. Flin P. and Vavilova I. B. Structure and properties of A1226, A1228, A1257. Astrophys. Lett. Commun. 1997. Vol. 36, No. 1-6. P. 113-117.

42. Gregul A. Ia., Mandzhos A. V., and Vavilova I. B. The existence of the structural anisotropy of the Jagiellonian field of the galaxies. Astrophys. Space Sci. 1991. Vol. 185, Is. 2. P. 223-235. DOI: $10.1007 / \mathrm{BF} 00643190$

43. Karachentseva V. E. and Vavilova I. B. Clustering of Low Surface Brightness Dwarf Galaxies in the Local Supercluster. In: Dwarf Galaxies, ESO Conf. and Workshop Proceedings. G. Meylan and P. Prugniel, eds. Garching: European Southern Observatory (ESO), 1994. P. $91-100$.

44. Vavilova I. B., Karachentseva V. E., Makarov D. I., and Melnyk O. V. Triplets of Galaxies in the Local Supercluster. I. Kinematic and Virial Parameters. Kinematika i Fizika Nebesnykh Tel. 2005. Vol. 21, No. 1. P. 3-20.

45. Lahav O., Fisher K. B., Hoffman Y., Scharpe C. A., and Zaroubi S. Wiener Reconstruction of All-Sky Galaxy Surveys in Spherical Harmonics. Astrophys. J. Lett. 1994. Vol. 423, Is. 2. P. L93. DOI: 10.1086/187244

46. Branchini E., Teodoro L., Frenk C. S., Schmoldt I., Efstathiou G., White S. D. M., Saunders W., Sutherland W., Rowan-Robinson M., Keeble O., Tadros H., Maddox S., and Oliver S. A non-parametric model for the cosmic velocity field. Mon. Not. R. Astron. Soc. 1999. Vol. 308, Is. 1. P. 1-28. DOI: 10.1046/j.1365-8711. 1999.02514.x
47. Vavilova I. and Melnyk O. Voronoi tessellation for galaxy distribution. In: "Voronoi's Impact on Modern Science" Mathematics and its Applications. Proc. of the Institute of Mathematics of the NAS of Ukraine. H. Syta, A. Yurachkivsky, and P. Engel, eds. Kyiv, Ukraine, 2005. Vol. 55. P. 203-212.

48. Melnyk O. V., Elyiv A. A., and Vavilova I. B. The structure of the Local Supercluster of galaxies detected by threedimensional Voronoi's tessellation method. Kinematika i Fizika Nebesnykh Tel. 2006. Vol. 22, No. 4. P. 283-296.

49. Elyiv A., Melnyk O., and Vavilova I. High-order 3D Voronoi tessellation for identifying isolated galaxies, pairs and triplets. Mon. Not. R. Astron. Soc. 2009. Vol. 394, Is. 3. P. 1409-1418. DOI: 10.1111/j.1365-2966.2008.14150.x

50. Dobrycheva D. V., Melnyk O. V., Vavilova I. B., and Elyiv A. A. Environmental Properties of Galaxies at $z<0.1$ from the SDSS via the Voronoi Tessellation. Odessa Astronomical Publications. 2014. Vol. 27. P. 26-27.

51. Cucciati O., Granett B. R., Branchini E., Marulli F., Iovino A., Moscardini L., Bel J., Cappi A., Peacock J. A., de la Torre S., Bolzonella M., Guzzo L., Polletta M., Fritz A., Adami C., Bottini D., Coupon J., Davidzon I., Franzetti P., Fumana M., Garilli B., Krywult J., Małek K., Paioro L., Pollo A., Scodeggio M., Tasca L. A. M., Vergani D., Zanichelli A., Di Porto C., and Zamorani G. The VIMOS Public Extragalactic Redshift Survey (VIPERS). Never mind the gaps: Comparing techniques to restore homogeneous sky coverage. Astron. Astrophys. 2014. Vol. 565. id. A67. DOI: 10.1051/0004-6361/ 201423409

52. Starck J. L, Pantin E., and Murtagh F. Deconvolution in Astronomy: A Review. Publ. Astron. Soc. Pac. 2002. Vol. 114, Is. 800. P. 1051-1069. DOI: $10.1086 / 342606$

53. Cantale N., Courbin F., Tewes M., Jablonka P., and Meylan G. Firedec: a two-channel finite-resolution image deconvolution algorithm. Astron. Astrophys. 2016. Vol. 589. id. A81. DOI: 10.1051/0004-6361/201424003

54. Savanevych V. E., Khlamov S. V., Vavilova I. B., Briukhovetskyi A. B., Pohorelov A. V., Mkrtichian D. E., Kudak V. I., Pakuliak L. K., Dikov E. N., Melnik R. G., Vlasenko V. P., and Reichart D. E. A method of immediate detection of objects with a near-zero apparent motion in series of CCD-frames. Astron. Astrophys. 2018. Vol. 609. id. A54. DOI: 10.1051/0004-6361/201630323

55. Schawinski K., Zhang C., Zhang H., Fowler L., and Santhanam G. K. Generative adversarial networks recover features in astrophysical images of galaxies beyond the deconvolution limit. Mon. Not. R. Astron. Soc. Lett. 2017. Vol. 467, Is. 1. P. L110-L114. DOI: 10.1093/mnrasl/ slx008

56. Goodfellow I., Pouget-Abadie J., Mirza M., Xu B., WardeFarley D., Ozair S., Courville A., and Bengio Y. Generative Adversarial Networks. In: Advances in Neural Information Processing Systems 27 (NIPS 2014). NIPS'14 Proceedings of the 27th International Conference on Neural Information Processing Systems 2014. 2014. vol. 2. P. 2672-2680. arXiv: 1406.2661

57. Dobrycheva D. V., Vavilova I. B., Melnyk O. V., and Elyiv A. A. Machine learning technique for morphological classification of galaxies at $z<0.1$ from the SDSS. E-print arXiv.org. 2017. arXiv:1712.08955 


\section{REFERENCES}

1. KRAAN-KORTEWEG, R. C. and LAHAV, O., 2000. The Universe behind the Milky Way. Astron. Astrophys. Rev. vol. 10, no. 3, pp. 211-261. DOI: 10.1007/ s001590000011

2. MAFFEI, P., 2003. My Researches at the Infrared Doors. Mem. S. A. It. vol. 74, no. 1, pp. 19-28.

3. SPINRAD, H., SARGENT, W. L. W., OKE, J. B., NEUGEBAUER, G., LANDAU, R., KING, I. R., GUNN, J. E., GARMIRE, G. and DIETER, N. H., 1971. Maffei 1: a New Massive Member of the Local Group? Astrophys. $J$. vol. 163, id. L25. DOI: 10.1086/180660

4. BUTA, R. J. and MCCALL, M. L., 1999. The IC 342/ Maffei Group Revealed. Astrophys. J. Suppl. Ser. vol. 124, pp. 33-93. DOI: 10.1086/313255

5. DAVIDGE, T. J. and VAN DEN BERGH, S., 2001. The Detection of Bright Asymptotic Giant Branch Stars in the Nearby Elliptical Galaxy Maffei 1. Astrophys. J. vol. 553, is. 2, id. L133. DOI: 10.1086/320692

6. HUCHTMEIER, W. K., LERCHER, G., SEEBERGER, R., SAURER, W. and WEINBERGER, R., 1995. Two new possible members of the IC342-Maffei1/2 group of galaxies. Astron. Astrophys. vol. 293, pp. L33-L36.

7. KARACHENTSEV, I. D., SHARINA, M. E., DOLPHIN, A. E. and GREBEL, E. K., 2003. Distances to nearby galaxies around IC 342. Astron. Astrophys. vol. 408, pp. 111-118. DOI: 10.1051/0004-6361:20030912

8. JARRETT, T. H., CHESTER, T., CUTRI, R., SCHNEIDER, S., ROSENBERG, J., HUCHRA, J. P. and MADER, J., 2000. 2MASS Extended Sources in the Zone of Avoidance. Astron. J. vol. 120, is. 1, pp. 298-313. DOI: $10.1086 / 301426$

9. LU, N. Y., DOW, M. W., HOUCK, J. R., SALPETER, E. E. and LEWIS, B. M., 1990. dentifying galaxies in the zone of avoidance. Astrophys. J. vol. 357, pp. 388-407. DOI: $10.1086 / 168929$

10. KRAAN-KORTEWEG, R. C., LOAN, A. J., BURTON, W. B., LAHAV, O., FERGUSON, H. C., HENNING, P. A. and BELL, L. D., 1994. Discovery of a nearby spiral galaxy behind the Milky Way. Nature. vol. 372, is. 6501, pp. 77-79.

11. BURTON, W. B., VERHEIJEN, M. A., KRAAN-KORTEWEG, R. C. and HENNING, P. A., 1996. Neutral hydrogen in the nearby galaxies Dwingeloo 1 and Dwingeloo 2. Astron. Astrophys. vol. 309, pp. 687-701.

12. HUCHTMEIER, W. K., LERCHER, G., SEEBERGER, R., SAURER, W. and WEINBERGER, R., 1995. Two new possible members of the IC342-Maffei1/2 group of galaxies. Astron. Astrophys. vol. 293L, pp. L33-L36.

13. KARACHENTSEV, I. D., 2005. The Local Group and Other Neighboring Galaxy Groups. Astron. J. vol. 129, no. 1 , pp. $178-188$. DOI: $10.1086 / 426368$

14. LAHAV, O., BROSCH, N., GOLDBERG, E., HAU, G. K. T., KRAAN-KORTEWEG, R. C. and LOAN, A. J., 1998. Galaxy candidates in the Zone of Avoidance. Mon. Not. R. Astron. Soc. vol. 299, is. 1, pp. 24-30. DOI: 10.1046/ j.1365-8711.1998.01686.x.

15. SAURER, W., SEEBERGER, R. and WEINBERGER, R., 1997. Penetrating the "zone of avoidance". IV. An optical survey for hidden galaxies in the region $-130^{\circ} \leq l \leq 130^{\circ}$, $-5^{\circ} \leq l \leq+5^{\circ}$. Astron. Astrophys. Suppl. Ser. vol. 126, no. 1, pp. 247-250. DOI: 10.1051/aas:1997385

16. BABYK, IU. V. and VAVILOVA, I. B., 2012. The Distribution of Baryon Matter in the Nearby X-ray Galaxy Clusters. Odessa Astronomical Publications. vol. 25, is. 2, P. 119-124.

17. BABYK, IU. V. and VAVILOVA, I. B., 2013. Comparison of Optical and X-ray Mass Estimates of the Chandra Galaxy Clusters at $z<0.1$. Odessa Astronomical Publications. vol. 26, pp. 175-178.

18. BABYK, IU. and VAVILOVA, I., 2014. The Chandra $\mathrm{X}$-ray galaxy clusters at $z<0.4$ : constraints on the evolution of $\mathrm{L}_{\mathrm{X}}-\mathrm{T}-\mathrm{M}_{\mathrm{g}}$ relations. Astrophys. Space Sci. vol. 349 , is. 1, pp. 415-421. DOI: $10.1007 /$ s10509-013-1630-Z

19. BABYK, IU. V., DEL POPOLO, A. and VAVILOVA, I. B., 2014. Chandra X-ray galaxy clusters at $z<0.4$ : Constraints on the inner slope of the density profiles. Astron. Rep. vol. 58, no. 9, pp. 587-610. DOI: 10.1134/ S1063772914090017

20. KOCEVSKI, D. D., EBELING, H. and MULLIS, C. R., 2003. Clusters in the Zone of Avoidance. In: J. S. MULCHAEY, A. DRESSLER, and A. OEMLER, eds. Carnegie Observatories Astrophysics Series. Vol. 3: Clusters of Galaxies: Probes of Cosmological Structure and Galaxy Evolution. [online]. [viewed 17.10.2018]. Available from: http://cds.cern.ch/record/614259/files/0304453.pdf

21. EBELING, H., JONES, L. R., FAIRLEY, B. W., PERLMAN, E., SCHARF, C. and HORNER, D., 2001. Discovery of a Very X-Ray Luminous Galaxy Cluster at $z=0.89$ in the Wide Angle ROSAT Pointed Survey. Astrophys. J. vol. 548, is. 1, pp. L23-L27. DOI: 10.1086/ 318915

22. KARACHENTSEV, I. D., MAKAROV, D. I. and KAISINA, E. I., 2013. Updated Nearby Galaxy Catalog. Astron. J. vol. 145, is. 4, id. 101. DOI: $10.1088 /$ 0004-6256/145/4/101

23. KASHIBADZE, O. G., KARACHENTSEV, I. D. and KARACHENTSEVA, V. E., 2014. Surveying the Local Supercluster Plane. Astrophys. Bull. vol. 73, no. 2, pp. 124-141. DOI: 10.1134/S1990341318020025

24. VAVILOVA, I. B., 2000. Wavelet analysis as approach to recognize abundance zone in galaxy distribution. Kinematika i Fizika Nebesnykh Tel. vol. 16(3), pp. 155.

25. ERDOĞDU, P. and LAHAV, O., 2009. Is the misalignment of the Local Group velocity and the dipole generated by the 2MASS Redshift Survey typical in $\Lambda$ cold dark matter and the halo model of galaxies? Phys. Rev. D. vol. 80, is. 4, id. 043005. DOI: $10.1103 /$ PhysRevD.80.043005

26. Kogut, A., LinewEAVER, C., SMoot, G. F., BENNETT, C. L., BANDAY, A., BOGGESS, N. W., CHENG, E. S., DE AMICI, G., FIXSEN, D. J., HINSHAW, G., JACKSON, P. D., JANSSEN, M., KEEGSTRA, P., LOEWENSTEIN, K., LUBIN, P., MATHER, J. C., TENORIO, L., WEISS, R., WILKINSON, D. T. and WRIGHT, E. L., 1993. Dipole anisotropy in the COBE DMR first year sky maps. Astrophys. J. vol. 419. DOI: $10.1086 / 173453$

27. GIOVANELLI, R. and HAYNES, M. P., 1985. A $21 \mathrm{~cm}$ survey of the Pisces-Perseus supercluster. I - The declina- 
tion zone +27.5 to +33.5 degrees. Astron. J. vol. 90 , is. 12 , pp. 2445-2473. DOI: $10.1086 / 113949$

28. KOLATT, T. and DEKEL, A., 1997. Large-scale power spectrum from peculiar velocities. Astrophys. J. vol. 479, no. 2, pp. 592-605.

29. VASYLENKO, M. YU. and KUDRYA, YU. N., 2017. Dipole bulk velocity based on new data sample of galaxies from the catalogue 2MFGC. Adv. Astron. Space. Phys. vol. 7, is. 1-2, pp. 6-11. DOI: 10.17721/2227-1481.7.6-11

30. KRAAN-KORTEWEG, R. C., CLUVER, M. E., BILICKI, M., JARRETT, T. H., COLLESS, M., ELAGALI, A., BÖHRINGER, H. and CHON, G., 2016. Discovery of a supercluster in the ZOA in Vela. Mon. Not. R. Astron. Soc. vol. 466, is. 1, pp. L29-L33. DOI: $10.1093 / \mathrm{mnrasl} /$ slw229

31. KRAAN-KORTEWEG, R. C., 2005. Cosmological Structures behind the Milky Way. In: S. RÖSER, ed. Reviews in Modern Astronomy 18: From Cosmological Structures to the Milky Way. New York: Wiley. pp. 48-75.

32. SAID, K., KRAAN-KORTEWEG, R. C., and JARRETT, T. H., 2014. Galaxy peculiar velocities in the Zone of Avoidance. In: R. BOTHA and T. JIL, eds. Proc. SAIP2013, the 58th Annual Conference of the South African Institute of Physics. arXiv:1410.2992

33. SAID, K., KRAAN-KORTEWEG, R. C., STAVELEYSMITH, L., WILLIAMS, W. L., JARRETT, T. H. and SPRINGOB, C. M., 2016. NIR Tully-Fisher in the Zone of Avoidance - II. $21 \mathrm{~cm}$ HI-line spectra of southern ZOA galaxies. Mon. Not. R. Astron. Soc. vol. 457, is. 3, pp. 2366-2376. DOI: 10.1093/mnras/stw105

34. SAID, K., KRAAN-KORTEWEG, R. C, JARRETT, T. H., STAVELEY-SMITH, L. and WILLIAMS, W. L., 2016. NIR Tully-Fisher in the Zone of Avoidance - III. Deep NIR catalogue of the HIZOA galaxies. Mon. Not. R. Astron. Soc. vol. 462, is. 3, pp. 3386-3400. DOI: 10.1093/ mnras/stw 1887

35. COURTOIS, H. M., HOFFMAN, Y., TULLY, R. B. and GOTTLÖBER, S., 2012. Three-dimensional Velocity and Density Reconstructions of the Local Universe with Cosmicflows-1. Astrophys. J. vol. 744, is. 1, id. 43. DOI: 10.1088/0004-637X/744/1/43.

36. SORCE, J. G., COLLESS, M., KRAAN-KORTEWEG, R. C. and GOTTLÖEBER, S., 2017. Predicting Structures in the Zone of Avoidance. Mon. Not. R. Astron. Soc. vol. 471, is. 3, pp. 3087-3097. DOI: $10.1093 / \mathrm{mnras} / \mathrm{st} \times 1800$

37. BEL, J., MARINONI, C., GRANETT, B. R, GUZZO, L., PEACOCK, J. A., BRANCHINI, E., CUCCIATI, O., DE LA TORRE, S., IOVINO, A., PERCIVAL, W. J., STEIGERWALD, H., ABBAS, U., ADAMI, C., ARNOUTS, S., BOLZONELLA, M., BOTTINI, D., CAPPI, A., COUPON, J., DAVIDZON, I., DE LUCIA, G., FRITZ, A., FRANZETTI, P., FUMANA, M., GARILLI, B., ILBERT, O., KRYWULT, J., LE BRUN, V., LE FÈVRE, O., MACCAGNI, D., MAŁEK, K., MARULLI, F., MCCRACKEN, H. J., PAIORO, L., POLLETTA, M., POLLO, A., SCHLAGENHAUFER, H., SCODEGGIO, M., TASCA, L. A. M., TOJEIRO, R., VERGANI, D., ZANICHELLI, A., BURDEN, A., DI PORTO, C., MARCHETTI, A., MELLIER, Y., MOSCARDINI, L., NICHOL, R. C., PHLEPS, S., WOLK, M. and ZAMORANI, G., 2014. The VIMOS Public Extragalactic Red- shift Survey (VIPERS) $\Omega_{\mathrm{m}_{0}}$ from the galaxy clustering ratio measured at $z \sim 1$. Astron. Astrophys. vol. 563, id. A37. DOI: $10.1051 / 0004-6361 / 201321942$

38. CUCCIATI, O., IOVINO, A., MARINONI, C., ILBERT, O., BARDELLI, S., FRANZETTI, P., LE FÈVRE, O., POLLO, A., ZAMORANI, G., CAPPI, A., GUZZO, L., MCCRACKEN, H. J., MENEUX, B., SCARAMELLA, R., SCODEGGIO, M., TRESSE, L., ZUCCA, E., BOTTINI, D., GARILLI, B., LE BRUN, V., MACCAGNI, D., PICA, J. P., VETTOLANI, G., ZANICHELLI, A., ADAMI, C., ARNABOLDI, M., ARNOUTS, S., BOLZONELLA, M., CHARLOT, S., CILIEGI, P., CONTINI, T., FOUCAUD, S., GAVIGNAUD, I., MARANO, B., MAZURE, A., MERIGHI, R., PALTANI, S., PELLÒ, R., POZZETTI, L., RADOVICH, M., BONDI, M., BONGIORNO, A., BUSARELlO, G., DE LA TORRE, S., GREGORINI, L., LAMAREILLE, F., MATHEZ, G., MELLIER, Y., MERLUZZI, P., RIPEPI, V., RIZZO, D., TEMPORIN, S. and VERGANI, D., 2006. The VIMOS VLT Deep Survey: the build-up of the colour-density relation. Astron. Astrophys. vol. 458, is. 1, pp. 39-52. DOI: 10.1051/0004-6361:20065161

39. ELYIV, A. A., 2006. UHECRs deflections in the IRAS PSCz catalogue based models of extragalactic magnetic field. Eprint arXiv.org. arXiv:astro-ph/0611696

40. VAVILOVA, I. B., 1997. Cluster and wavelet analysis for detachment of the structure of galaxy cluster: comparison. In: V. DI GESU, M. J. B. DUFF, A. HECK, M. C. MACCARONE, L. SCARSI and H. U. ZIMMERMAN, eds. Data Analysis in Astronomy, Proc. of the Fifth Workshop. World Scientific Press, pp. 297-302.

41. FLIN, P. and VAVILOVA, I. B., 1997. Structure and properties of A1226, A1228, A1257. Astrophys. Lett. Commun. vol. 36, no. 1-6, pp. 113-117.

42. GREGUL, A. IA., MANDZHOS, A. V. and VAVILOVA, I. B., 1991. The existence of the structural anisotropy of the Jagiellonian field of the galaxies. Astrophys. Space Sci. vol. 185, is. 2, pp. 223-235. DOI: 10.1007/BF00643190

43. KARACHENTSEVA, V. E. and VAVILOVA, I. B. , 1994. Clustering of Low Surface Brightness Dwarf Galaxies in the Local Supercluster. In: G. MEYLAN and P. PRUGNIEL, eds. Dwarf Galaxies, ESO Conf. and Workshop Proceedings. Garching: European Southern Observatory (ESO), pp. 91-100.

44. VAVILOVA, I. B., KARACHENTSEVA, V. E., MAKAROV, D. I. and MELNYK, O. V., 2005. Triplets of Galaxies in the Local Supercluster. I. Kinematic and Virial Parameters. Kinematika i Fizika Nebesnykh Tel. vol. 21, no. 1, pp. 3-20.

45. LAHAV, O., FISHER, K. B., HOFFMAN, Y., SCHARPE, C. A. and ZAROUBI, S., 1994. Wiener Reconstruction of All-Sky Galaxy Surveys in Spherical Harmonics. Astrophys. J. Lett. vol. 423, is. 2, pp. L93. DOI: 10.1086/ 187244

46. BRANCHINI, E., TEODORO, L., FRENK, C. S., SCHMOLDT, I., EFSTATHIOU, G., WHITE, S. D. M., SAUNDERS, W., SUTHERLAND, W., ROWAN-ROBINSON, M., KEEBLE, O., TADROS, H., MADDOX, S. and OLIVER, S., 1999. A non-parametric model for the cosmic velocity field. Mon. Not. R. Astron. Soc. vol. 308, is. 1 , pp. 1-28. DOI: $10.1046 / \mathrm{j} .1365-8711.1999 .02514 . \mathrm{x}$ 
47. VAVILOVA, I. and MELNYK, O., 2005. Voronoi tessellation for galaxy distribution. In: H. SYTA, A. YURACHKIVSKY, and P. ENGEL, eds. "Voronoi's Impact on Modern Science" Mathematics and its Applications. Proc. of the Institute of Mathematics of the NAS of Ukraine. Kyiv, Ukraine, 2005. vol. 55, pp. 203-212.

48. MELNYK, O. V., ELYIV, A. A. and VAVILOVA, I. B., 2006. The structure of the Local Supercluster of galaxies detected by three-dimensional Voronoi's tessellation method. Kinematika i Fizika Nebesnykh Tel. vol. 22, no. 4, pp. 283-296.

49. ELYIV, A., MELNYK, O. and VAVILOVA, I., 2009. High-order 3D Voronoi tessellation for identifying isolated galaxies, pairs and triplets. Mon. Not. R. Astron. Soc. vol. 394, is. 3, pp. 1409-1418. DOI: $10.1111 /$ j.1365-2966.2008.14150.x

50. DOBRYCHEVA, D. V., MELNYK, O. V., VAVILOVA, I. B. and ELYIV, A. A., 2014. Environmental Properties of Galaxies at $z<0.1$ from the SDSS via the Voronoi Tessellation. Odessa Astronomical Publications. vol. 27, pp. 26-27.

51. CUCCIATI, O., GRANETT, B. R., BRANCHINI, E., MARULLI, F., IOVINO, A., MOSCARDINI, L., BEL, J., CAPPI, A., PEACOCK, J. A., DE LA TORRE, S., BOLZONELLA, M., GUZZO, L., POLLETTA, M., FRITZ, A., ADAMI, C., BOTTINI, D., COUPON, J., DAVIDZON, I., FRANZETTI, P., FUMANA, M., GARILLI, B., KRYWULT, J., MAŁEK, K., PAIORO, L., POLLO, A., SCODEGGIO, M., TASCA, L. A. M., VERGANI, D., ZANICHELLI, A., DI PORTO, C. and ZAMORANI, G., 2014. The VIMOS Public Extragalactic Redshift Survey (VIPERS). Never mind the gaps: Comparing techniques to restore homogeneous sky coverage. Astron. Astrophys. vol. 565, id. A67. DOI: 10.1051/0004-6361/ 201423409

52. STARCK, J. L, PANTIN, E. and MURTAGH, F., 2002. Deconvolution in Astronomy: A Review. Publ. Astron. Soc. Pac. vol. 114, is. 800, pp. 1051-1069. DOI: $10.1086 / 342606$

53. CANTALE, N., COURBIN, F., TEWES, M., JABLONKA, P. and MEYLAN, G., 2016. Firedec: a two-channel finite-resolution image deconvolution algorithm. Astron. Astrophys. vol. 589, id. A81. DOI: 10.1051/0004-6361/ 201424003

54. SAVANEVYCH, V. E., KHLAMOV, S. V., VAVILOVA, I. B., BRIUKHOVETSKYI, A. B., POHORELOV, A. V., MKRTICHIAN, D. E., KUDAK, V. I., PAKULIAK, L. K., DIKOV, E. N., MELNIK, R. G., VLASENKO, V. P. and REICHART, D. E., 2018. A method of immediate detection of objects with a near-zero apparent motion in series of CCD-frames. Astron. Astrophys. vol. 609, id. A54. DOI: 10.1051/0004-6361/201630323

55. SCHAWINSKI, K., ZHANG, C., ZHANG, H., FOWLER, L. and SANTHANAM, G. K., 2017. Generative adversarial networks recover features in astrophysical images of galaxies beyond the deconvolution limit. Mon. Not. R. Astron. Soc. Lett. vol. 467, is. 1, pp. L110-L114. DOI: $10.1093 / \mathrm{mnrasl} / \mathrm{sl}$ x008

56. GOODFELLOW, I., POUGET-ABADIE, J., MIRZA, M., XU, B., WARDE-FARLEY, D., OZAIR, S., COURVILLE, A. and BENGIO, Y., 2014. Generative Adversarial Networks. In: Advances in Neural Information Processing Systems 27 (NIPS 2014). NIPS'14 Proceedings of the 27th
International Conference on Neural Information Processing Systems 2014.vol. 2, pp. 2672-2680. arXiv:1406.2661 57. DOBRYCHEVA, D. V., VAVILOVA, I. B., MELNYK, O. V. and ELYIV, A. A., 2017. Machine learning technique for morphological classification of galaxies at $\mathrm{z}<0.1$ from the SDSS. E-print arXiv.org. arXiv:1712.08955

\section{И. Б. Вавилова, А. А. Эльии, М. Ю. Василенко}

Главная астрономическая обсерватория НАН Украины, ул. Академика Заболотного, 27, г. Киев, 03143, Украина

\section{ЗА ЗОНОЙ ИЗБЕГАНИЯ МЛЕЧНОГО ПУТИ: ЧТО МОЖНО ВОССОЗДАТЬ ПРЯМЫМИ И НЕПРЯМЫМИ МЕТОДАМИ?}

Предмет и иеель работы: представить краткий обзор методов, которые применяются для восстановления распределения крупномасштабных структур Вселенной за зоной избегания (ZoA) Млечного Пути; предложить новый “алгоритм штопки зоны избегания” и новый подход, основанный на Генерирующих состязательных сетях (GAN) для восстановления распределения галактик в ZoA с использованием оптических обзоров в качестве дополнительной платформы для программирования искусственных нейронных сетей.

Методы и методология: Благодаря мониторинговым наблюдениям всего неба в радио (проект DOGS, наблюдение в линии HI), инфракрасном (IRAS и 2MASS обзоры) и рентгеновском спектральных диапазонах, ZoA “уменьшилась” в размерах и закрывает от наблюдателя около 10 \% пространственного распределения галактик в оптическом диапазоне. Измерения реликтового излучения (CMB) показали асимметрию в $180^{\circ}$, известную как диполь: несмотря на то, что результирующий вектор находится в пределах $20^{\circ}$ наблюдаемого диполя СМВ, расчеты остаются весьма неоднозначными, отчасти потому, что не учитываются галактики в ZоA и концепция “аттракторов” требует пересмотра. На сегодняшний день анализ пространственного распределения галактик и их групп в областях, окружающих зону избегания галактик, остается сложной и нерешенной проблемой, а оценка “невидимого” пространственного распределения галактик, которое закрывает от наблюдателя зона поглощения, - крайне своевременной. Для восстановления распределения галактик в ZоА можно использовать косвенные методы, включая методы обработки сигналов, применяемые к скрытым и неполным данным; методы мозаики Вороного и т. д. Эти методы восстановления, однако, работают только для крупномасштабных структур в зоне избегания галактик; они практически не чувствительны к отдельным галактикам и малонаселенным скоплениям галактик. Одним из решений является использование методик машинного обучения, например GAN, для моделирования "невидимого" пространственного распределения галактик за этой зоной. Pезультаты: Мы предлагаем новый подход, названный нами “алгоритм штопки зоны избегания”, для разбивания существующих внегалактических обзоров (например, SDSS DR 14) на срезы в зависимости от красного смещения, звездных величин, координат и других параметров для формирования тренировочной выборки машинного обучения, а также описываем общую схему GAN метода для применения 
к восстановлению ZoA. Мы обсуждаем основные задачи генерирования искусственных распределений галактик и их свойств в ZoA и описываем, как дискриминационная сеть будет сравнивать полученное распределение с реальным и оценивать его реалистичность.

Заключение: Неполнота данных, зависящая от длины волны, на которой проводились обзоры, говорит о том, что остались такие проблемы, как динамика Местной Группы и ближней Вселенной; крупномасштабная структура Вселенной в области неба, скрытой нашей Галактикой; поля потоков скоростей галактик к Великому Аттрактору; диполь СМВ. Мы предлагаем новый “алгоритм штопки зоны избегания” и общую схему GAN в качестве дополнительной платформы машинного обучения для восстановления пространственного распределения за зоной избегания нашей Галактики.

Ключевые слова: крупномасштабная структура Вселенной, Млечный Путь, галактики, скопления галактик, зона избегания галактик, машинное обучение, генерирующая состязательная сеть (GAN), “алгоритм штопки зоны избегания”

\section{І. Б. Вавилова, А. А. Елиїв, М. Ю. Василенко}

Головна астрономічна обсерваторія НАН України, вул. Академіка Заболотного, 27, м. Київ, 03143, Україна

\section{ЗА ЗОНОЮ УНИКНЕННЯ ЧУМАЦЬКОГО ШЛЯХУ: ЩО МОЖНА ВІДТВОРИТИ ПРЯМИМИ I НЕПРЯМИМ МЕТОДАМИ?}

Предмет і мета роботи: подати короткий огляд методів, які застосовуються для відтворення розподілу великомасштабних структур Всесвіту за зоною уникнення (ZoA) Чумацького Шляху;запропонувати новий “алгоритм штопання зони уникнення” і новий підхід, що грунтується на генеруючій змагальній мережі (GAN) для відновлення розподілу галактик в ZoA з використанням оптичних оглядів у якості додаткової платформи для програмування штучних нейронних мереж.

Методи і методологія: Завдяки моніторинговим спостереженнями всього неба в радіо (проект DOGS, спостереження в лінії HI), інфрачервоному (IRAS та 2MASS огляди) і рентгенівському спектральних діапазонах, ZoA “зменшила" свої розміри і наразі закриває від спостерігача близько 10 \% просторового розподілу галактик в оптичному діапазоні. Вимірювання реліктового випромінювання (СМВ) показали асиметрію в $180^{\circ}$, відому як диполь: незважаючи на те, що результуючий вектор знаходиться в межах $20^{\circ}$ спостережуваного диполя СМВ, розрахунки залишаються досить неоднозначними, почасти тому, що не враховуються галактики в ZoA і концепція “атракторів” вимагає перегляду. Наразі аналіз просторового розподілу галактик і їх скупчень у областях, що оточують зону уникнення галактик, залишається складною і невирішеною проблемою, а оцінка “невидимого" просторового розподілу галактик, яке закриває від спостерігача зона поглинання, є вкрай своєчасною. Для відновлення розподілу галактик в ZoА можливе використання непрямих методів, включаючи методи обробки сигналів, що застосовуються до прихованих і неповних даних; методи мозаїки Вороного тощо. Ці методи відновлення, проте, працюють тільки для великомасштабних структур в зоні уникнення галактик; вони практично не чутливі до окремих галактик і малонаселених скупчень галактик. Одним з рішень є використання методик машинного навчання, наприклад GAN, для моделювання “невидимого” просторового розподілу галактик за цією зоною.

Результати: Ми пропонуємо новий підхід, названий нами “алгоритм штопання зони уникнення”, для розбивання існуючих позагалактичних оглядів (наприклад, SDSS DR 14) на зрізи залежно від червоного зміщення, зоряних величин, координатів та інших параметрів для формування тренувальної вибірки машинного навчання, а також описуємо загальну схему GAN методу для застосування до відновлення ZoA. Ми обговорюємо основні завдання генерування штучних розподілів галактик та їх властивостей в ZoA i описуємо, як дискримінаційна мережа буде порівнювати отриманий розподіл з реальним і оцінювати його реалістичність.

Висновок: Неповнота даних, що залежить від довжини хвилі, на якій виконувалися огляди, свідчить про те, що залишилися такі проблеми, як динаміка Місцевої Групи і ближнього Всесвіту; великомасштабна структура Всесвіту в області неба, прихованою нашою Галактикою; поля потоків швидкості галактик до Великого Атрактора; диполь СМВ. Ми пропонуємо новий “алгоритм штопання зони уникнення” і загальну схему GAN в якості додаткової платформи машинного навчання для відновлення просторового розподілу галактик за зоною уникнення нашої Галактики.

Ключові слова: великомасштабна структура Всесвіту, Чумацький Шлях, галактики, скупчення галактик, зона уникнення галактик, машинне навчання, генеруюча змагальна мережа (GAN), “алгоритм штопання зони уникнення”

Received 19.10.2018 